\title{
Floodgate Operations and Fish Communities in Tidal Creeks of the Lower Fraser River (British Columbia, Canada)
}

\author{
Rebecca E. Seifert ${ }^{1}$ - Jonathan W. Moore $^{1}$ \\ Received: 8 May 2016 / Revised: 25 June 2017 / Accepted: 16 August 2017 / Published online: 3 October 2017 \\ (C) The Author(s) 2017. This article is an open access publication
}

\begin{abstract}
Tidal creeks in large coastal deltas can be important habitat for fish but are often highly modified by human activities. Connectivity between tributary creeks and mainstem channels is often constrained by structures such as dikes and floodgates, designed to protect urban and agricultural areas from flooding. While they play important roles in flood mitigation, floodgates can diminish habitat quality and block fish from accessing tidal creeks. It is likely that floodgates differ in their operations and may consequently open for different amounts of time; however, floodgate operations and their effects are not well quantified. We asked the question: how does the mechanical functioning of these floodgates affect fish communities in tidal creeks? We used time-lapse cameras and quantified the timing of gate openings for 22 tributaries of the Lower Fraser River in British Columbia, Canada, and related these operational data to differences in fish communities above and below floodgates. Floodgate operations varied substantially, with some floodgates opening daily while others opened less than $20 \%$ of the day, on average. Sites with floodgates that seldom opened were associated with greater differences in fish communities and with reduced upstream native species richness by about one species on average. Where floodgates opened infrequently, we also found lower upstream
\end{abstract}

Communicated by Nadine A. Strydom

Electronic supplementary material The online version of this article (https://doi.org/10.1007/s12237-017-0313-3) contains supplementary material, which is available to authorized users.

Rebecca E. Seifert

rseifert@sfu.ca

1 Earth to Ocean Research Group, Simon Fraser University, 8888 University Drive, Burnaby, BC V5A 1S6, Canada dissolved oxygen concentrations than at sites where floodgates opened for longer periods of time. Thus, floodgate operations can influence fish communities as well as water quality. These data indicate a large scope for improving floodgate operations for connectivity.

Keywords Flood mitigation · Fish · Tide gates · Impoundment $\cdot$ Connectivity $\cdot$ Salmon

\section{Introduction}

One of the key challenges of coastal floodplain management is providing flood protection while maintaining ecosystem connectivity and integrity. Coastal floodplains and estuaries are among the most diverse and productive ecosystems on the planet but have also been dramatically altered over a long history of human settlement (Tockner and Stanford 2002; Lotze et al. 2006). Cities located in coastal deltas are prone to floods on two fronts: from the ocean and from upriver. This flood risk has led to extensive development of flood control infrastructure to protect property and people from flood damages. Flood control structures typically consist of dikes or levees along river mainstems, with floodgates and pumping stations installed at tributaries to allow drainage out to sea while preventing the river or tides from backing up water levels behind the dikes. Given that these coastal floodplains also provide important rearing habitat for numerous juvenile fishes in tidal creeks and wetlands (Beck et al. 2001), there is a need for science that can guide fish-friendly flood protection.

Floodgates are a key structure for flood protection across the world but also can influence connectivity between rivers and their tributaries (Giannico and Souder 2005). Floodgates, also known as tide gates or flood boxes, are culverts with a flap gate on the downstream end that closes when water levels 
in the river mainstem rise above water levels in the tributary. In the majority of cases, floodgates will open only when there is a sufficient head differential across the gates, with enough water accumulated above the gates to overcome the weight of the gate, the friction in the hinges, and the pressure exerted on the flap gates by downstream water levels (Giannico and Souder 2005; Thomson 2005). Thus, floodgates generally close with the rising tide and open with the falling tide, though they can remain closed for weeks at a time in river systems during seasonal flood events (Thomson 2005). Floodgates can sever connectivity within tidal floodplains, with negative consequences for water quality, fish passage, and biodiversity (Giannico and Souder 2004; Kroon and Ansell 2006; Scott et al. 2016), and therefore highlight the challenges of balancing flood protection and floodplain connectivity.

Floodgates may impact fishes in two main ways: altering water quality and restricting fish passage (Kroon and Ansell 2006). First, floodgates can alter water quality by restricting tidal exchange (Raposa and Roman 2003; Ritter et al. 2008). Floodgates are associated with hypoxic dead zones due to eutrophication in the stagnant upstream habitats (Portnoy 1991; Gordon et al. 2015). Impounded water in tidal creeks also tends to have higher concentrations of nutrients, fecal coliforms, and heavy metals, as well as high turbidity and siltation rates (Giannico and Souder 2004; Portnoy and Allen 2006). Second, when closed, floodgates physically restrict fish passage, impeding migratory fishes from entering or leaving tidal creeks (Bass 2010; Doehring et al. 2011; Wright et al. 2014). These impacts may together contribute to the observed alterations to fish communities associated with floodgates around the world (Pollard and Hannan 1994; Halls et al. 1998; Scott et al. 2016). In Australia's lower Clarence River, for example, gated creeks had lower richness and abundance of commercially important fish and crustacean species than un-gated tidal creeks (Pollard and Hannan 1994; Kroon and Ansell 2006). Furthermore, non-native fishes, many of which may be more tolerant of poor water quality, have been found in greater numbers above floodgates in New Zealand and on the west coast of North America (Franklin and Hodges 2012; Scott et al. 2016).

Modifying floodgate operations to allow for greater connectivity could reduce negative impacts on fish and fish habitats while maintaining flood protection capacity. Fish and crustacean communities may respond to improvements in tidal exchange following removals of dikes and culverts by becoming more similar to communities found in fully connected creeks (Raposa and Roman 2003; Boys and Williams 2012). Increasing tidal exchange across floodgates may reduce negative impacts by improving water quality and allowing estuary-dependent fish to recolonize tidal creeks (Boys et al. 2012). Numerous design and management options have been proposed to alleviate the impacts of floodgates, including barrier removal, replacement with alternative designs, and new management routines to allow floodgates to open for longer periods of time (Pollard and Hannan 1994; Giannico and Souder 2004). For example, self-regulating tide gates use floats to remain open for a longer portion of the tidal cycle (Giannico and Souder 2005). Alternatively, manually leaving some floodgates open except during periods of high flood risk could improve flushing and fish passage (Franklin and Hodges 2015). A study in Oregon and Washington State demonstrated a correlation between the density of Chinook salmon and other estuary-dependent species and the "connectedness" across tide gates (an index based on the tide gate's opening size and duration) (Greene et al. 2012). Furthermore, Wright et al. (2014) found that opening floodgates for longer periods of time may reduce delays in sea trout passage in the UK's River Meon. Modifying floodgate operations may therefore be a promising option for mitigating their negative impacts on fish.

Despite recent interest in alternative flood infrastructure and management options, there are limited data available on floodgate operations. Many studies on floodgate impacts have compared biotic and abiotic characteristics of gated and reference creeks, without quantifying differences among the floodgates and their impacts on water quality and fish communities (Pollard and Hannan 1994; Kroon and Ansell 2006; Scott et al. 2016). Thomson (2005) quantified gate opening for a few floodgates in the Lower Mainland of British Columbia (BC), Canada, and observed that side-mounted gates appeared to open more often than top-mounted gates. A handful of studies from other systems have quantified floodgate operations for a limited number of sites or over short time periods (e.g., Bass 2010; Greene et al. 2012). However, sampling at greater spatial and temporal scales is needed to understand how much variation exists in floodgate operations and how this relates to potential differences in fish communities or water quality.

The lower Fraser River in southern BC exemplifies the challenges of balancing flood protection and fish habitat in coastal floodplains. The Fraser River is the longest river in BC, draining more than a quarter of the province, and has historically supported some of the world's largest runs of Pacific salmon (Northcote and Larkin 1989). Furthermore, the Fraser watershed is home to over 2.7 million people, representing more than half the population of BC (Fraser Basin Council 2010a). Most of this population resides in the Lower Fraser region, which has over 400 floodgates and $600 \mathrm{~km}$ of dikes to protect urban and rural areas from flooding (Fraser Basin Council 2010b). Although we know that many floodgates may remain closed for weeks to months during seasonal high flows (i.e., the freshet) (Thomson 2005), there are limited data on floodgate operations for the rest of the year. Tidal creeks and wetlands represent important rearing habitats for juvenile coho and Chinook salmon (Oncorhynchus kisutch, O. tshawytscha) (Levy and Northcote 1982; Craig et al. 2014); however, floodgates can diminish water quality and restrict access to these habitats (Gordon et al. 2015; Scott et al. 2016). Given aging 
infrastructure and increased flood risk due to sea level rise and changing river hydrographs, the region is undergoing a strategic flood management planning process (Fraser Basin Council 2014). Thus, the Fraser River system is one key example of a region where studies of floodgate operations and impacts could inform infrastructure upgrades or mitigation efforts.

We compared the floodgate operations and fish communities of tidal creeks in the Lower Fraser region to answer two questions: (1) How do floodgates differ in their operation (i.e., the amount of time gates are open)? (2) How do floodgate operations influence fish communities and water quality in gated tributaries? To assess floodgate operation, we used time-lapse photography from July 2014 to July 2015 to quantify when gates were open or closed. We also sampled fish communities above and below the floodgates to determine how the relative differences in upstream fish communities varied with gate operations. Given that there are a variety of floodgate designs and management regimes, we hypothesized that floodgate openness would vary widely, with some gates remaining closed most of the time and other gates opening daily with the changing tides. We also hypothesized that where gates are open for longer periods of time on average, fish communities found upstream of the floodgates would be more similar to those found downstream of the floodgates. Collectively, these data can be used to identify opportunities to move towards fish-friendly flood protection.

\section{Methods}

\section{Site Selection}

For this study, we sampled 22 tributaries in the Lower Fraser region, including tributaries that flow directly into the Fraser
River as well as those that flow into the Pitt, Coquitlam, and Harrison rivers (rivers that flow into the lower Fraser River). Of these, 18 sites had floodgates of various designs and configurations and four had no floodgates (Fig. 1, Online Resource 1). These non-floodgate sites were chosen to represent fully connected habitats. Candidate sites were selected after reviewing the Lower Fraser Strategic Streams Review (DFO 1999) and Lower Fraser River floodplain maps (BC MFLNRO 2011). Site selection criteria included accessibility for sampling, availability of preexisting data on floodgate opening or a suitable place to secure a time-lapse camera, and a sufficient channel width and length to conduct two seine hauls in the tributary on either side of the floodgates.

\section{Quantifying Floodgate Operations}

There is a limited amount of data on floodgate operations in the Lower Fraser, with most published data limited to a few sites and short time frames. Here, we addressed this data gap on floodgate opening and closing by compiling existing data from municipalities and by using time-lapse photography to capture floodgate position at 1-h intervals. Only two sites had available preexisting data-Spencer Creek and Mountain Slough - both of which are controlled manually based on threshold water levels. As such, staff at the District of Kent and the City of Maple Ridge provided opening and closing dates during the study period. At the remaining 16 floodgate sites, we installed Brinno TLC200 time-lapse cameras to photograph the floodgates every daylight hour from July 2014 to January 2015, and then again from April to July 2015. Cameras were removed from January to April 2015 to avoid losing cameras due to vandalism and water damage during particularly high tides or winter storms, when large volumes

Fig. 1 A map of the locations of sampling sites within the Lower Fraser region of British Columbia, Canada. Filled circles indicate sites with floodgates and open circles sites without floodgates

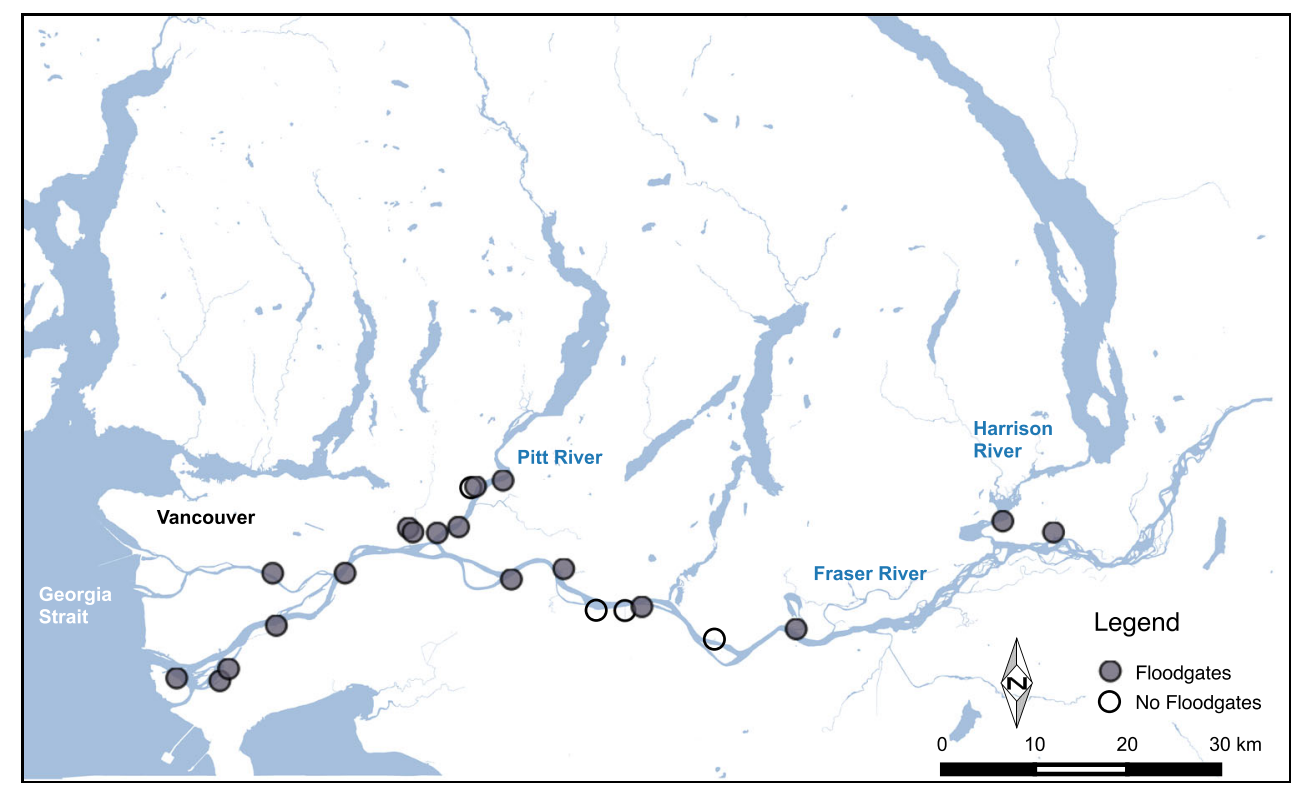


of water are pumped over the dikes. Once every 4-6 weeks, we visited the sites to check the cameras, change batteries, and download the photos. Cameras were mounted inside of a PVC pipe housing and locked to railings, grates, or fences around the floodgates. Despite attempts to protect cameras within this housing, some data were missing for some sites and time periods due to theft, water damage, and the camera shifting positions.

The collected time-lapse videos were reviewed frame-by-frame to assess gate openness. The gates were described as open or closed based on a minimum threshold of openness set when water was able to visibly flow between the edge of the gate and any adjacent structures such as walls or other gates (typically a $\sim 5^{\circ}-10^{\circ}$ opening angle). In Oregon, juvenile coho salmon have been observed passing through a top-hinged floodgate while it was open to angles of $7^{\circ}$ $16^{\circ}$ (Bass 2010). Although larger fish may be unable to move through floodgates that are only open $5^{\circ}-10^{\circ}$, the majority of fish captured in this study were under $40 \mathrm{~mm}$ fork length, and a wider minimum opening may exclude times when these fish can pass through the floodgates.

Many flood boxes have multiple gates (Online Resource 1), but due to flood box configurations and limited camera mounting positions, we were not able to photograph all gates at all sites. Where possible, we photographed all of the floodgates at a site and classified the flood box as open when at least one floodgate opened. If it was not possible to fit all of the floodgates in the frame, we randomly selected one or one pair of floodgates and mounted the camera to photograph the representative gate or pair of gates (Online Resource 1). High tides or river levels frequently submerged floodgates completely, obscuring them from the view of the cameras. When floodgates were completely under water, we assumed the pressure from the high downstream water level was keeping the gates closed. In order to open, floodgates must have sufficient head differential (i.e., pressure due to differences in water level), with enough water accumulated above the gates to overcome friction in the hinges and the pressure of water downstream of the floodgates holding them closed (Giannico and Souder 2005; Thomson 2005). In the time-lapse footage, floodgates typically closed before the water fully submerged them and were also closed when the tide receded several hours later (personal observation). Furthermore, most floodgates are accompanied by pumping stations that remove excess water from upstream when the downstream water level is high (Thomson 2005), thereby reducing the hydraulic head and the likelihood that floodgates would open when underwater. Accordingly, we are confident that this approach provides reliable information on patterns of floodgate operation.

To quantify floodgate operations, we calculated the proportion of the recording time (i.e., daytime hours) that the floodgates opened for each date and site, and then took the mean value across the entire video recording period (July 2014
July 2015). We calculated the proportion of the day that gates were open instead of counting the number of hours. This was to account for the cameras' inability to record images at night and the rapidly changing day lengths in the autumn months at this temperate latitude. We also calculated the "mean proportion of the day gates opened" over subset time periods (e.g., data from July and August only) and based on a stricter gate openness threshold $\left(\sim 30^{\circ}\right.$ opening angle), but found that all openness metrics were highly correlated $\left(r^{2}>0.85\right)$, and did not include these other metrics in further analyses.

\section{Fish Sampling}

We sampled fish at all sites to understand how floodgate operations influenced fish communities. Each site was sampled once between July 30 and August 29, 2014. Previous studies in the area have identified late summer as a period when the impacts of flood boxes on fish and water quality are most severe (Gordon et al. 2015; Scott et al. 2016).

At each site, we sampled fish communities with four seine hauls using a $15.24 \mathrm{~m}$ by $2.44 \mathrm{~m}$ net with a $3.175-\mathrm{mm}$ mesh size. At sites with floodgates, we performed two seine hauls on each side of the floodgates (upstream and downstream). To conduct these seine hauls, one crew member held one end of the net on the bank near the water's edge while another member waded with the other end towards the center of the channel and then back to shore, where crewmembers quickly pulled up the excess net onto the bank and formed a purse to hold the captured fish. The net was fully extended during each set to keep the set area relatively consistent and comparable. Some sites were too deep to safely wade with the seine net. At these locations, we rowed an inflatable raft to pull one edge of the seine net while the other end was held at the waters' edge. Captured fish were removed from the net, identified to species, measured to fork length, and weighed before being released back to the location of capture. Sampling was approved by the University Animal Care Committee at Simon Fraser University (protocol number 1158B-11) and by scientific collection permits from Fisheries and Oceans Canada and the Ministry of Forests, Lands, and Natural Resource Operations.

Exact locations of seine hauls were chosen based on practical and biological reasons. At the four sites without floodgates, seines were conducted approximately $30-50 \mathrm{~m}$ apart and on either side of a place that might have had a floodgate. For example, dikes can often occur under railroads or roads, but at the sites without floodgates, bridges were installed over an interruption in the dike rather than floodgates. Exact seine locations were selected based on the ability to pull the seine net up on the bank (influenced by slope of bank), safe access to the shoreline, and the need to be a safe distance from pump intakes and outfalls. As much as possible, we selected seine locations to represent one or two habitat types and attempted to find similar habitats upstream and downstream where they 
existed. At some sites, seine locations were limited by short channel length, woody debris snagging the net, and water depth. Furthermore, our sampling may have been affected by differences in capture efficiency during sampling, as well as the volume of water sampled. Although we made efforts to sample a similar-sized area during each set, there were variations in water depths and tides across sites. Due to time restrictions and the high number of sampling sites spread over a large geographic area, we were unable to standardize our sampling to occur at the same tidal stage and depth across all sites.

In addition to fish data, we recorded water quality data, channel width and depth, and weather conditions at each site. Using a YSI device (Model 556 MPS, YSI Incorporated 2009), we measured dissolved oxygen, salinity, conductivity, and temperature at a distance of $15 \mathrm{~m}$ from the flood box on its upstream and downstream sides. The YSI probe was placed near the middle of the channel at a depth of approximately $0.5 \mathrm{~m}$. These measurements were collected once at each site during fish community sampling.

\section{Geographic Site Information: Watershed Area, Distance Upriver, and Land Use}

This analysis included three geographic variables that may affect fish abundance and diversity: distance up the Fraser River from the ocean to the floodgate, watershed area upstream of the floodgates, and land use within each site's watershed. Distance upriver was estimated using the Path and Measurement tools within Google Earth to draw and measure a path along the river to the mouth of the river (version 7.1.5.1557, Google Inc 2015). Because the Fraser River splits into north, middle, and south arms in the delta, we took the measurement via the arm that produced the shortest path from the ocean to the floodgates. Watershed areas were estimated in ArcGIS version 10.2 (ESRI 2014) after drawing watershed polygons with the Hydrology tools. In several cases, the watershed's topography was too flat for the Hydrology tools to correctly draw the watershed boundaries. In these cases, we drew watershed boundaries manually while referencing aerial photos from Google Earth. We summed the land use areas within each watershed into four categories: Agricultural, Urban, Undeveloped, and Other Human Uses (e.g., industrial, transportation, resource extraction, and utilities). The developed percentage of the watershed was obtained by summing the percent areas of all agricultural, urban, and other human land uses (Online Resource 1). Metro Vancouver, the District of Kent, the Fraser Valley Regional District, and the District of Mission provided land use data for their respective jurisdictions.

\section{Statistical Analysis}

We conducted two main analyses to (a) examine patterns in gate openings and explore what site characteristics could affect gate openings and (b) to understand how differences in fish communities on either side of the dikes relate to floodgate openness. These analyses also included several site characteristics as variables (Online Resource 1). We also conducted a third analysis to determine whether water quality measurements (e.g., dissolved oxygen concentrations) relate to floodgate operations.

We constructed generalized linear mixed-effects models (GLMMs) to determine whether site characteristics affected the amount of time gates opened. Given that the response data were repeated observations of whether the gates were open or closed, we used the binomial family with a logit-link for this model set. Gate opening data were summarized by date, with the model input formatted as a two-column integer matrix containing the proportions of the day that floodgates were open and closed (Hastie and Pregibon 1992). Initial model comparisons based on Akaike's information criterion (AIC) indicated strong support for including the daily mean discharge of the Fraser River (Water Survey of Canada station no. 08MH024) as a covariate in all candidate models. Specifically, including daily mean discharge reduced the model's AIC score by $30.2 \Delta$ AIC units. In addition, all models incorporated a random intercept by site $(\triangle \mathrm{AIC}=213.7$ with a lower AIC score for the model with the random effect) and an AR1 temporal autocorrelation term $(\triangle \mathrm{AIC}=9626.6$ with a lower AIC score for the model with the autocorrelation term) based on results of initial model comparisons between models with and without each of these terms. These three factors were then included in all models in a different set of candidate models, which were compared using AIC model selection to determine which fixed effects were best supported by the data. Candidate models included all subsets of the following fixed effects: distance from the ocean, watershed area, pumps (present/absent), gate type (side-hinged, tophinged, or manual sliding gate), and the proportion of the watershed with developed land uses. The continuous variables were standardized by their sample standard deviations and centered to aid in model convergence (Schielzeth 2010). The model set also included a "null" model with only the autocorrelation term, daily mean Fraser discharge, and the random effect. No interaction terms were considered due to poor coverage of some variables (e.g., pumps present in larger watersheds but not smaller ones) and failure of models to converge. Models were created using the lme4 package (v. 1.1-9, Bates et al. 2015) in R (v. 3.1.2, R Core Team 2015).

To examine potential relationships among site-level variables, we conducted a principle component analysis using PAST (v. 2.17, Hammer et al. 2012). These variables included floodgate type, pump presence or absence, watershed area, location on the river, and percentage of the watershed with developed land uses.

We calculated differences between the upstream and downstream fish communities using community dissimilarity metrics and log response ratios. First, we sought to understand 
how the entire fish communities differed upstream and downstream of floodgates and to investigate how these community differences varied with floodgate operations (i.e., are communities more different where floodgates stay closed?). To do this, we constructed a community dissimilarity matrix using Bray-Curtis differences, taking each upstream/downstream section as a separate site. Given that fish samples were dominated heavily by three-spined stickleback (Gasterosteus aculeatus), we square-root-transformed taxon abundances before calculating Bray-Curtis distances, as this metric can be driven by abundances of a dominant species (Legendre and Legendre 2012). Bray-Curtis distances for the upstream and downstream portions of each site were then extracted from the community dissimilarity matrix for further analysis against floodgate operations. Bray-Curtis dissimilarities were computed using the vegan package in R (v. 2.3-0, Oksanen et al. 2015).

To characterize potential differences between upstream and downstream fish communities, we computed the log response ratios of several metrics based on fish samples. These metrics included the richness, biomass, and number of fish captured upstream and downstream of floodgates. We calculated these metrics for total fish captured and for subgroups of fishes (e.g., native and non-native fishes). The log response ratio $(\ln R R)$ is typically used to express the effects of a treatment relative to a control or reference state (Hedges et al. 1999). Here, we treat the downstream fish community as a reference state and the upstream fish community as a treatment, to compute the log response ratio as

$\ln R R=\ln \left(1+\frac{\text { Upstream-downstream }}{\text { Downstream }}\right)$

To test whether the downstream fish communities would be suitable for use as the "reference state," we plotted downstream fish captures, biomass, and richness against floodgate openness. We did not find any strong relationships between openness and downstream fish variables, thus we are confident that the log response ratio is an effective metric for this purpose.

After breaking the data out into groups of species (e.g., native or non-native fishes), several sample units had zero values and resulted in undefined or infinite estimates of the log response ratio. These zero values are potentially important features of the data, so we added the minimum non-zero value for that variable to every observation before calculating the log response ratio. This method of adjustment has been used as a conservative estimate of the log response ratio in data where species were not detected in some samples (Viola et al. 2010). We also computed log response ratios for the richness, biomass, and number captured for the four most commonly sampled taxa: three-spined stickleback (Gasterosteus aculeatus), pumpkinseed sunfish (Lepomis gibbosus), prickly sculpin (Cottus asper), and juvenile minnows (Cyprinidae). We captured many unidentified juvenile cyprinids (most of which were under 40$\mathrm{mm}$ fork length), and therefore pooled them with all minnows for calculations of fish taxonomic richness.

The computed Bray-Curtis distances and log response ratios were then used as response variables in a series of linear models to understand relationships between upstream-downstream community differences and floodgate openness. A separate set of candidate models was created for each of the response variables (e.g., species richness, abundance). Each of the candidate models included up to two of the following explanatory variables: mean proportion of the day gates opened, number of floodgates, watershed area, distance upriver, and the percent developed area in the watershed. Top models were selected based on small sample-size corrected AIC (AICc) values, and parameter estimates were obtained by averaging models within $8 \Delta$ AICc units of the top model (Burnham and Anderson 2002). Before model averaging, we checked that the candidate models met the assumptions of linear modeling by examining residuals and normal Q-Q plots.

We also used linear modeling to explore whether floodgate operations were correlated to water quality measurements. We constructed a series of linear models relating dissolved oxygen concentrations to floodgate operations and site characteristics. All models for dissolved oxygen measurements appeared to meet the assumptions of linear modeling, based on residuals, normal Q-Q plots, and Cook's distances. These models were compared using AICc model comparison and parameter values and weights were estimated using model averaging. We used the direct measurements and modeled upstream and downstream dissolved oxygen separately. For all analyses, model selection and averaging were performed with the AICcmodavg (v. 2.0-3, Mazerolle 2015) and MuMIn (v. 1.15.1, Bartoń 2015) packages implemented R (v. 3.1.2, R Core Team 2015).

Following from these results, we were interested in whether hypoxic conditions above floodgates might affect the differences in observed fish communities at gated sites. In a posthoc analysis, we examined the fish community data for a relationship with upstream dissolved oxygen concentrations. Neither Bray-Curtis community differences nor the log response ratios for native richness showed strong correlations with upstream dissolved oxygen concentrations $\left(r^{2} \sim 0.1\right.$, $p>0.05$ ).

\section{Results}

Time-lapse camera footage, combined with preexisting data from two sites, revealed high levels of variability in operation of floodgates in this region. Many of the floodgates were closed almost all of the time - approximately $40 \%$ of all sites had floodgates that opened for less than $10 \%$ of the day on average (Fig. 2). While most sites opened infrequently or for 
Fig. 2 Histogram showing the frequency of sites by the annual average proportion of daylight hours that their floodgates opened. Reference sites without floodgates were not included in this figure

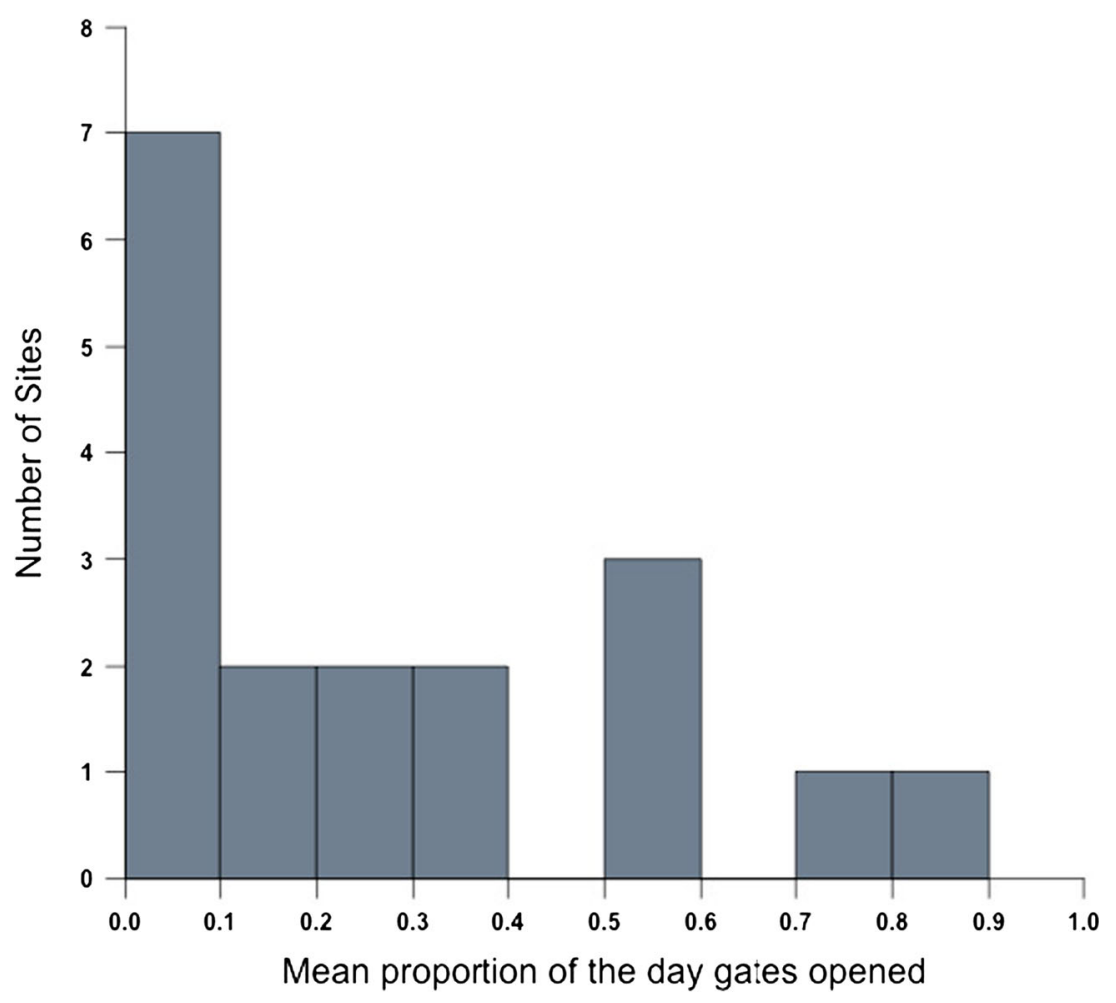

short periods of time, five of these 18 sites $(\sim 30 \%)$ opened for more than half of the day on average. Thus, there is a wide range of existing variation in floodgate operations in this region.

There were seasonal patterns in floodgate openings, where many floodgates remained closed for most of the Fraser River freshet in July 2014 and again from mid-May through June 2015, but opened and closed more sporadically during the rest of the year (Fig. 3, Online Resource 2). Floodgate opening patterns also appeared to vary regionally, with sites closer to the ocean possibly showing more of a tidal signature and those further upriver more closely following the freshet patterns (Fig. 3b-f).

Fraser River discharge was the only factor that was consistently supported for explaining patterns of floodgate operations, with an inverse relationship between mean daily discharge and floodgate opening time (Table 1, Fig. 3), such that gates were closed more during periods of high flow. The top model included distance upriver, Fraser River discharge, and the temporal autocorrelation parameter as fixed effects, but since competing models had somewhat similar support ( $\triangle \mathrm{AIC}<8$ ), we report the unconditional model-averaged coefficients and parameter weights (Table 1). Mean discharge was the only parameter with confidence intervals not intersecting zero. Site-level factors received much less support than flow for their ability to explain gate openness patterns. Although the distance from the floodgate to the ocean may have some influence on gate openness, it received only $53 \%$ of the support based on model-averaged fixed effects.
We explored potential relationships among flood box characteristics, site location, and watershed land use with principal component analysis (PCA). The PCA analyses revealed that pumps seem to be placed at floodgates situated in larger, more developed watersheds (Fig. 4) - where controlling large volumes of water requires pumps in addition to the floodgates. Differing gate types did not appear to correlate strongly with other site-level factors.

We captured a total of 7531 fish across all sites during our sampling between July 30 and August 27, 2014 (Online Resource 3). Most of the fish captured were likely juveniles of their species, as over $75 \%$ of all fish captured had a fork length of less than $40 \mathrm{~mm}$. Over half of the fish captured were threespine stickleback (Gasterosteus aculeatus, 4697 in total), and 1319 were unidentified juvenile cyprinids. We also captured the following native freshwater fishes: northern pikeminnow (Ptychocheilus oregonensis), prickly sculpin (Cottus asper), peamouth chub (Mylcheilus caurinus), largescale sucker (Catostomus macrocheilus), brassy minnow (Hybognathus hankinsoni), redside shiner (Richardsonius balteatus), bull trout (Salvelinus confluentus), cutthroat trout (Oncorhynchus clarkii), and mountain whitefish (Prosopium williamsoni). We captured a few juvenile salmon-11 chum (Oncorhynchus keta) and 17 coho (O. kisutch) - in the sampling period. At sites closer to the mouth of the river, we captured two species native to local marine and estuarine ecosystems - starry flounder (Platichthys stellatus) and shiner surfperch (Cymatogaster aggregata), as well as an unidentified juvenile flatfish. We also captured five species of non- 


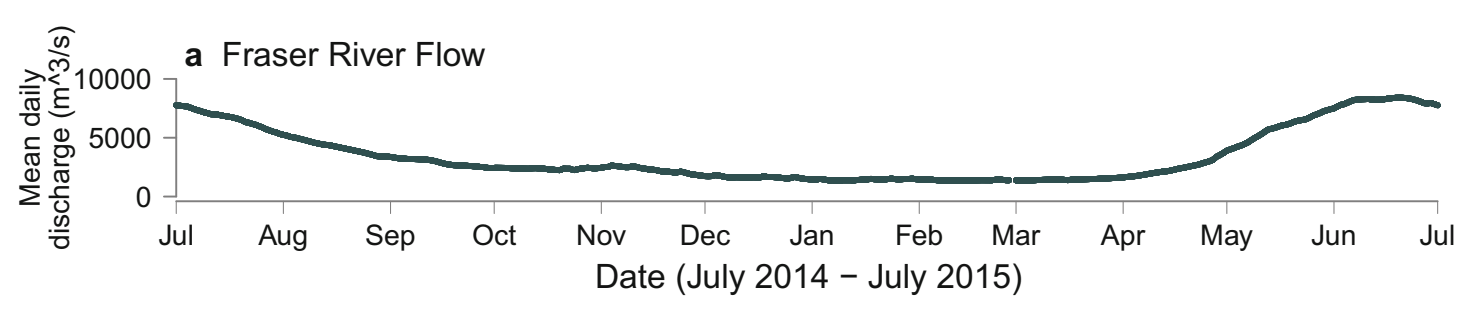

Gate Openings
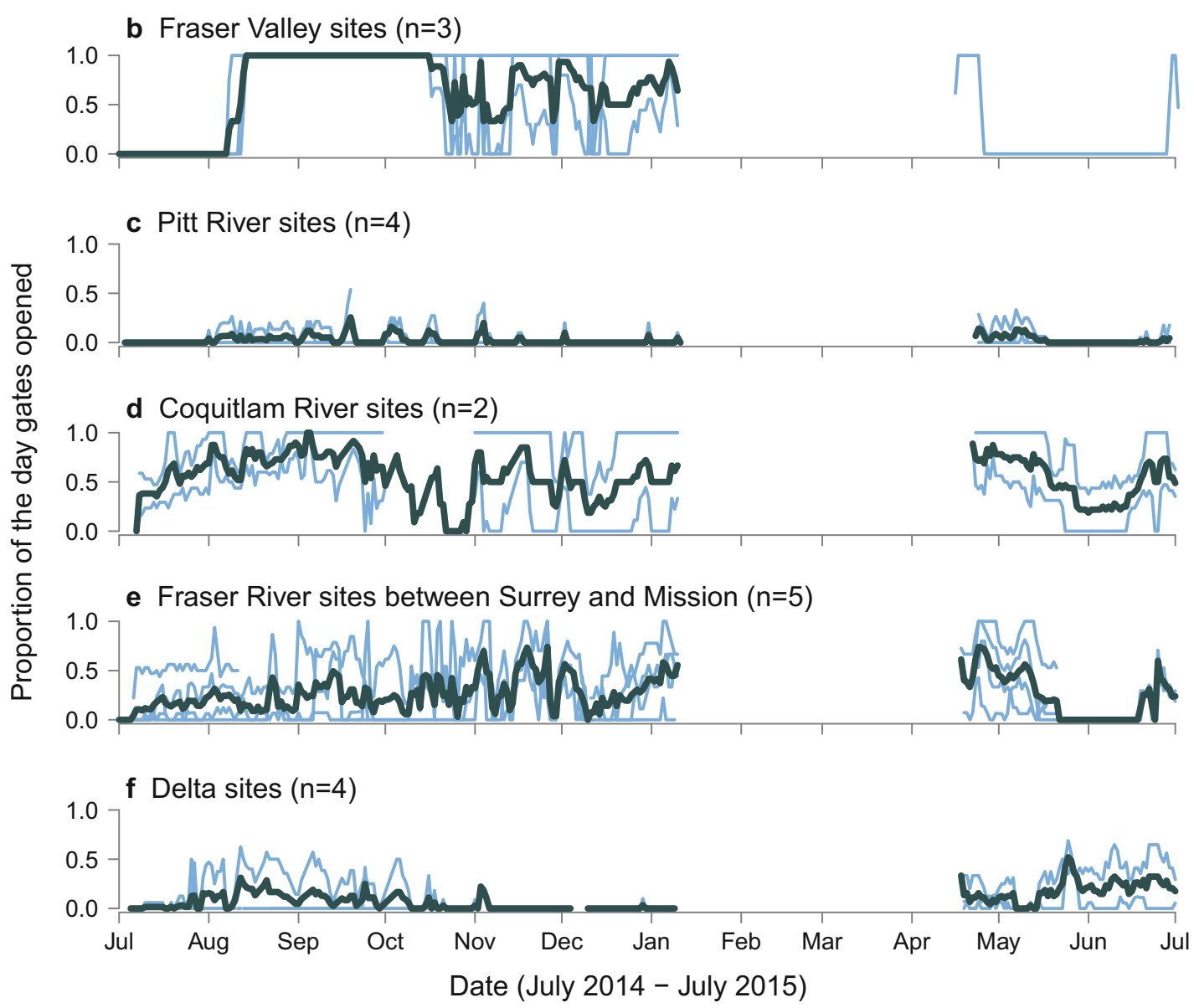

Fig. 3 Time series of a daily mean discharge in the Fraser River at Mission (data courtesy of the Water Survey of Canada station no. 08MH024); b-f proportion of each day the floodgates opened in different sections of the Lower Fraser. Lighter lines represent individual sites' time series, while the dark bolded lines represent the average across sites for that subregion. Site groupings are roughly listed from sites furthest upriver (b) to sites that are closest to the ocean (f). Data were not collected during the blank period to avoid losing cameras due to vandalism and water damage during winter storms that can lead to high water levels in the tributaries

(0.69) while site covariates received much less relative support (Table 2). The model-averaged openness parameter estimate was the only one with confidence intervals excluding zero. Based on model-averaged results, upstream and downstream fish communities were on average $23 \%$ more similar (less dissimilar) in fully connected sites when compared to sites where floodgates never or rarely opened (Table 2). Calculated BrayCurtis dissimilarities ranged from 22.4 to $82.4 \%$ dissimilar communities above and below floodgates. At McLean Creek, for example, floodgates opened for $1.7 \%$ of the day on average and the Bray-Curtis dissimilarity was $82.4 \%$. At this site, we 
Table 1 Summary of AIC model averaging output for a set of binomial generalized linear mixed models (GLMMs) comparing floodgate openness with the watershed area of the tributary, the distance from the ocean to the tributary, the percentage of the sub-watershed that has been developed, the type of floodgate, and whether pumps are present or absent

\begin{tabular}{lcclc}
\hline Parameter & $\begin{array}{l}\text { Parameter } \\
\text { estimate }\end{array}$ & $\begin{array}{l}95 \% \text { Confidence } \\
\text { interval }\end{array}$ & $\begin{array}{l}\text { Parameter } \\
\text { weight }\end{array}$ & $\begin{array}{l}\text { No. of models } \\
\text { with parameter }\end{array}$ \\
\hline Intercept (manual gates, no pumps) & -0.29 & -1.02 to 0.45 & NA & 32 \\
Mean discharge $\left(\mathrm{m}^{3} / \mathrm{s}\right)$ & -0.13 & -0.17 to -0.08 & 1.00 & 32 \\
ARl temporal component & 1.09 & 1.06 to 1.12 & 1.00 & 32 \\
Distance upriver $(\mathrm{km})$ & 0.26 & -0.07 to 0.59 & 0.53 & 16 \\
Pumps (present) & -0.20 & -1.06 to 0.67 & 0.30 & 16 \\
Watershed area $\left(\mathrm{km}^{2}\right)$ & 0.06 & -0.29 to 0.41 & 0.29 & 16 \\
\% Watershed with developed land use & 0.03 & -0.39 to 0.45 & 0.28 & 16 \\
Gate type & - & - & 0.23 & 16 \\
• Manual sluice gate & -0.32 & -1.38 to 0.73 & & \\
• Side-hinged & -0.7397 & -1.98 to 0.50 & & \\
- Top-hinged & & & \\
\hline
\end{tabular}

All models included Fraser River mainstem discharge and an AR1 temporal autocorrelation term. For each parameter, the table lists estimates, $95 \%$ confidence intervals, weights, and the number of models with that parameter. Italicized rows indicate parameters where the $95 \%$ confidence interval did not include zero

${ }^{\text {a }}$ The base model was for a site with manual floodgates and no pumps captured two taxa upstream of the floodgates (66\% largemouth bass, 33\% sunfish), and five taxa downstream (43\% sunfish, $41 \%$ cyprinids, and $16 \%$ individuals from three other native taxa that did not overlap). In contrast, at Silverdale Creek-a site where there are no floodgates and the communities are fully connected - the upstream and downstream communities had a Bray-Curtis dissimilarity of $26.9 \%$. There, we captured seven taxa in the upstream reach (72\% sunfish, $16 \%$ cyprinids, $6 \%$ sculpin, and $6 \%$ from four other native taxa), and six taxa in the downstream reach (67\% sunfish, $18 \%$ sculpin, $2 \%$ brown bullhead, and $13 \%$ from three other native taxa). We note that two sites had relatively low dissimilarity even though they opened infrequently (Fig. 5); stickleback were particularly numerically abundant in these two sites, a species which this study and previous have found to be tolerant of floodgates.

Floodgates that were more open also had higher relative native taxonomic richness (Fig. 6a, Table 2). The data supported an effect of openness over other site-level covariates (Table 2). The model-averaged openness parameter estimate was the only parameter to have confidence intervals not crossing zero. This model indicated that sites with low floodgate openness tended to have fewer native taxa upstream of the floodgates relative to downstream. Sites where floodgates opened very rarely (intercept $=0$, i.e., never) would on average have $32 \%$ fewer fish taxa upstream of the floodgates. On average, we found 3.5 (s.d. = 1.26) native fish taxa downstream of floodgates. After back-calculating from the log response ratio, this result would, on average, translate to approximately one fewer native taxa upstream if floodgates never opened. This model shows a relative increase in upstream native richness as floodgate openness increases, with little to no difference in upstream-downstream native richness where there are no floodgates. Conversely, AICc model selection and averaging results did not show substantial support for an effect of floodgate operations on differences in the richness of nonnative fishes (parameter weight $=0.17$, Fig. 6 b, Table 3 ).

Floodgate openness did not appear to be an important factor for explaining upstream-downstream differences in overall fish counts, biomass, or taxonomic richness. For all of these response variables, the intercept-only (null) model was the top model or ranked within two $\triangle \mathrm{AICc}$ units of the top model, indicating that neither floodgate operations nor other site characteristics were important for explaining the differences in these variables above and below floodgates. Additionally, neither the site-level covariates nor floodgate openness appeared to have any effect on the response ratios of biomass or counts of native or non-native fish. Online Resource 4 summarizes the richness, biomass, and number of fish captured (grouped by total, native, and non-native fish).

We did not detect a substantial effect of floodgate openness on response ratios of captures or biomass for the three most common fish groups captured-three-spine stickleback, juvenile cyprinids, and sunfishes. The log response ratio for prickly sculpin (Cottus asper) captures, however, indicated that relatively few sculpins were captured above floodgates that seldom opened compared to areas where they opened for longer periods (Table 2). If floodgates never opened, the model would estimate the upstream number of prickly sculpins at approximately one quarter of that found downstream, but if floodgates opened $80 \%$ of the day, on average, there would be little to no difference in sculpin numbers above and below floodgates.

Dissolved oxygen concentrations were on average lower above floodgates than below (Fig. 7), with concentrations averaging at $4.11($ s.d. $=2.91) \mathrm{mg} / \mathrm{L}$ above floodgates and at 
Fig. 4 a Principle component analysis (PCA) ordination plot displaying relationships between site characteristics. Symbols represent the presence (filled squares) or absence (open squares) of pumping stations at a floodgate site. Vectors represent the loadings for the number of floodgates, the watershed area, the percentage of the watershed with developed land uses, and the distance from the ocean to the floodgate, labeled clockwise from the top. The lower two panels show the loadings for the first principal component (b) and the second principal component (c)
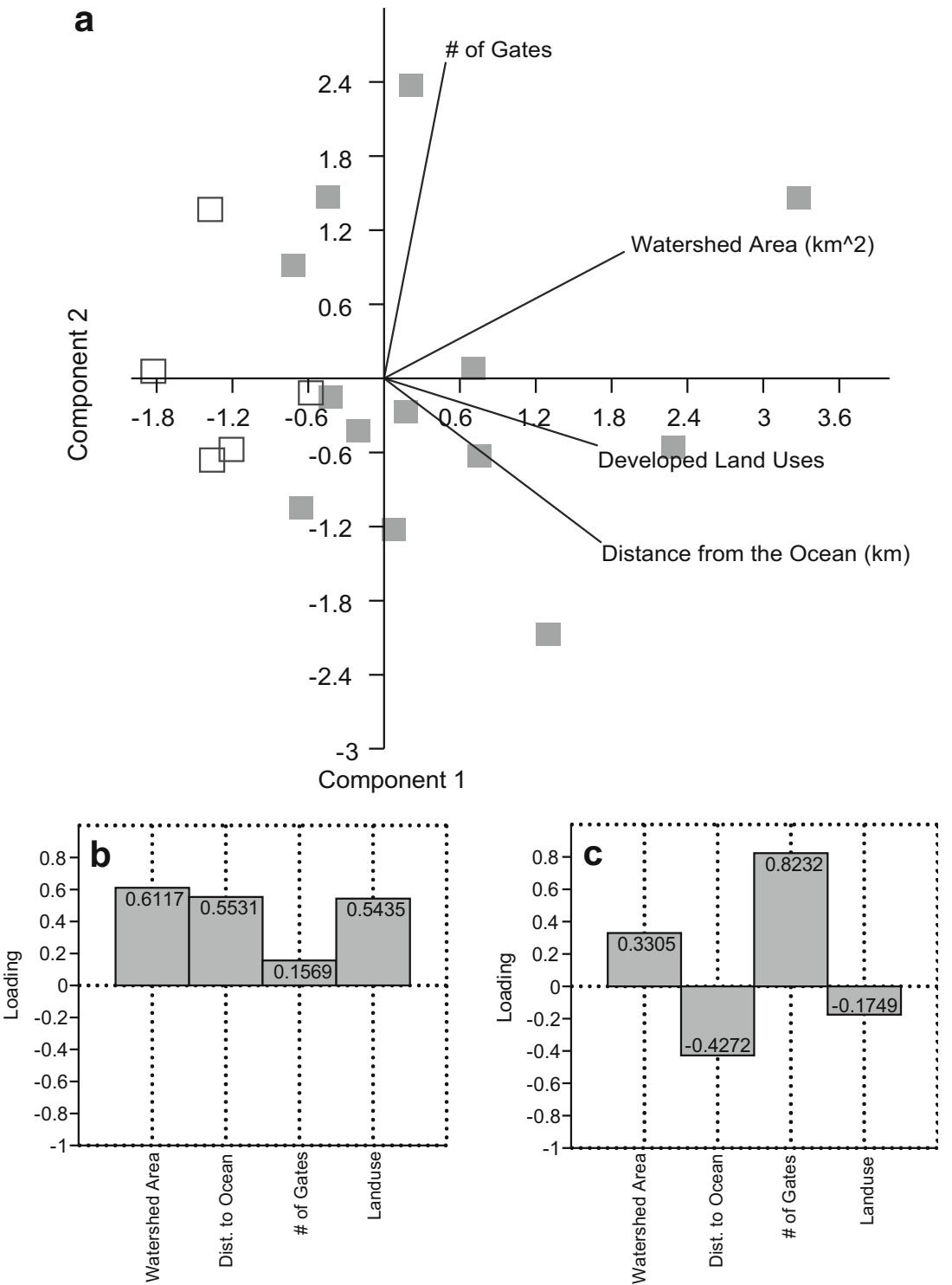

6.77 (s.d. $=2.79) \mathrm{mg} / \mathrm{L}$ below floodgates. Linear modeling indicated that upstream dissolved oxygen concentrations were greater on average where floodgates opened more frequently or in sites without floodgates (Fig. 7, Table 3). Models that included floodgate openness ranked highly based on deltaAIC scores. Model averaging estimated a parameter weight of 0.93 , indicating a high degree of support for an effect of floodgate operations on upstream dissolved oxygen. Based on the model-averaged parameter estimate for floodgate openness (Table 3), dissolved oxygen concentrations were on average 5.9 times lower in reaches above floodgates that never or rarely opened compared to fully open sites. Linear models and AICc model averaging indicated little support for an effect of floodgate operations on downstream dissolved oxygen concentrations (Table 3 ). Other water quality parameters (temperature, conductivity, and salinity) did not exhibit relationships with floodgate operations and site characteristics.
In an additional set of analyses, we examined whether summer (July/August) floodgate operations were effective predictors of fish communities and upstream dissolved oxygen concentrations. Results were qualitatively similar to our main analysis using averages based on the full year's floodgate operations data (Online Resource 5). However, the relationships between floodgate openness and fish community differences (native fish richness and community dissimilarities) were less certain when considering the shorter period, as the confidence intervals for this parameter overlapped zero.

\section{Discussion}

This study discovered considerable variation in floodgate operations in the Lower Fraser River area of British Columbia, Canada, and that these operations are linked to impacts on fish 


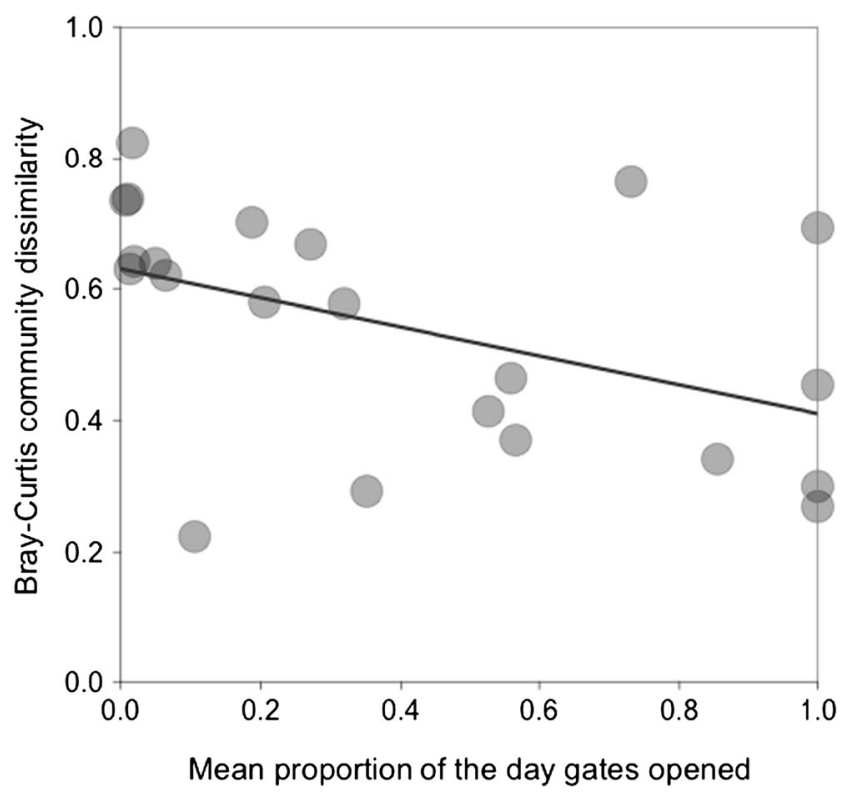

Fig. 5 Fish community change as a function of floodgate operation. This figure shows the Bray-Curtis dissimilarity of fish communities upstream vs. downstream of floodgates (or equivalent sampling locations for un-gated sites). Values closer to 1 indicate more different fish communities while values closer to 0 indicate more similar fish communities. Floodgate operations are represented by the mean proportion of the day gates opened at each site, such that values closer to one are, on average, open for a longer portion of the day. The line presented here represents the singlevariable linear model comparing Bray-Curtis dissimilarities with floodgate operations (not the full model) and is meant for visualization purposes

biodiversity and water quality. Floodgate operations varied substantially across sites, with most floodgates opening for less than one quarter of the day on average. Differences in fish communities above and below floodgates were more pronounced where floodgates were closed for more time. Furthermore, in sites where floodgates seldom opened, upstream fish communities had relatively fewer native species than at sites where floodgates opened more often. Additionally, dissolved oxygen concentrations were lower upstream of floodgates that seldom opened. These findings provide evidence that impacts to water quality and fish communities can vary with the operations of gates. Accordingly, there may be opportunities to mitigate impacts to tidal creek water quality and fish communities by altering floodgate operations.

\section{Floodgate Operations}

We found substantial variation in the operations of floodgates throughout the region, with several floodgates remaining closed for weeks and others opening daily. While some floodgates opened for more than $50 \%$ of the day on average, almost half of the floodgates in this study opened for less than $20 \%$ of the day on average (Fig. 2). Some of this variation may reflect the local management practices, with different designs and management routines employed in different locales (Bass 2010; Fraser Basin Council 2010a). The seasonal patterns of floodgate openings appeared to vary throughout the Lower Fraser region (Fig. 3), especially with respect to the spring high-flow period (i.e., freshet). Other work has noted that floodgates positioned closer to the ocean are more likely to be controlled by tidal cycles (LGL Limited et al. 2009). Although the Fraser River is tidal to $\sim 115 \mathrm{~km}$ from the ocean (Levings et al. 1995), the strength of the tides diminishes at locations further upriver. The data showed a trend towards floodgates opening longer on average at sites further upriver, and this could reflect differences in the influence of the freshet and the tides. Topography and floodgate elevation may be factors contributing to this spatial variation in operational patterns. For example, many floodgates are situated in areas built upon reclaimed wetlands (rather than on creeks or sloughs) that historically would have been inundated for much of the year; therefore, the gates are kept closed to keep the reclaimed land dry. This study provides new information for understanding floodgate operations across a range of sites, adding to previous studies in the area (Thomson 2005).

We found that higher flows in the Fraser River were associated with floodgates being closed more. The hydrology of the Fraser River is characterized by snowmelt-driven high flow in the spring and early summer, with typical daily mean discharge rates around $8000 \mathrm{~m}^{3} / \mathrm{s}$ at its peak, compared to $700 \mathrm{~m}^{3} / \mathrm{s}$ in low flow months (i.e., winter) (Levy and Northcote 1982). Indeed, many floodgates were closed during the freshet (i.e., for the first half of July 2014 and in 2015 for part of May and June). Historically, up to 20,000 ha of wetland and slough habitat in the Lower Fraser were flooded annually, most likely during the spring freshet (Birtwell et al. 1988). Understandably, the spring freshet is a major concern for flood managers, such that several floodgates are manually closed for this period. However, the late spring/early summer period is also when juvenile salmon redistribute themselves to tidal portions of watersheds to rear before leaving for the ocean (Levy and Northcote 1989; Levings et al. 1995). When floodgates are closed, juvenile salmon cannot enter tributary habitats, and may therefore be deprived of further opportunities to grow before entering the ocean. Furthermore, closed floodgates mean that smolts can only leave gated tributaries via pumps, where they are likely to be injured or killed (Thomson 1999). Thus, the temporal pattern of floodgate closures suggests disproportionately large impacts on juvenile salmon.

The specifics of floodgate design and management are often discussed when considering how to alleviate impacts on fish passage and water exchange (Giannico and Souder 2005; Boys et al. 2012). For example, lightweight side-mounted gates have been recommended over cast iron top-mounted gates, as they tend to open wider and more readily with changing water levels (Thomson 2005). Manually operated sluice gates have also been recommended as they can be left open except during periods of high flood risk (Pollard and Hannan 1994). This study, however, did not find substantial support 
Table 2 Summary of AICc model averaging output for analyses of fish community responses versus floodgate operation data and site characteristics

\begin{tabular}{|c|c|c|c|c|}
\hline Response variable & Parameter & $\begin{array}{l}\text { Parameter } \\
\text { estimate }\end{array}$ & $\begin{array}{l}\text { 95\% Confidence } \\
\text { interval }\end{array}$ & $\begin{array}{l}\text { Parameter } \\
\text { weight }\end{array}$ \\
\hline \multirow[t]{6}{*}{ Bray-Curtis community dissimilarities } & Intercept & 0.60 & 0.41 to 0.80 & $N A$ \\
\hline & Mean proportion open & -0.23 & -0.43 to -0.03 & 0.69 \\
\hline & Watershed area $\left(\mathrm{km}^{2}\right)$ & 0 & -0.01 to 0.00 & 0.27 \\
\hline & Number of floodgates & 0.02 & -0.05 to 0.08 & 0.17 \\
\hline & $\%$ Watershed with developed land use & 0.08 & -0.30 to 0.46 & 0.13 \\
\hline & Distance upriver $(\mathrm{km})$ & 0.00 & 0.00 to 0.00 & 0.13 \\
\hline \multirow[t]{6}{*}{ Native species richness log response ratio } & Intercept & -0.39 & -0.91 to 0.11 & NA \\
\hline & Mean proportion open & 0.55 & 0.05 to 1.05 & 0.63 \\
\hline & Number of floodgates & -0.09 & -0.22 to 0.04 & 0.27 \\
\hline & Watershed area $\left(\mathrm{km}^{2}\right)$ & -0.01 & -0.02 to 0.00 & 0.27 \\
\hline & Distance upriver $(\mathrm{km})$ & 0.00 & -0.01 to 0.01 & 0.13 \\
\hline & $\%$ Watershed with developed land use & -0.10 & -1.01 to 0.81 & 0.12 \\
\hline \multirow[t]{6}{*}{ Non-native species richness log response ratio } & Intercept & -0.13 & -0.76 to 0.56 & NA \\
\hline & Number of floodgates & 0.11 & -0.01 to 0.22 & 0.49 \\
\hline & $\%$ Watershed with developed land use & 0.58 & -0.32 to 1.47 & 0.25 \\
\hline & Watershed area $\left(\mathrm{km}^{2}\right)$ & 0.01 & 0.00 to 0.02 & 0.23 \\
\hline & Mean proportion open & -0.21 & -0.83 to 0.41 & 0.17 \\
\hline & Distance Upriver (km) & 0.00 & -0.01 to 0.01 & 0.16 \\
\hline \multirow[t]{6}{*}{ Prickly sculpin catch log response ratio } & Intercept & -1.40 & -3.33 to 0.54 & NA \\
\hline & Mean proportion open & 1.72 & 0.17 to 3.27 & 0.53 \\
\hline & Distance upriver $(\mathrm{km})$ & 0.02 & 0.00 to 0.04 & 0.44 \\
\hline & $\%$ Watershed with developed land use & -1.80 & -4.78 to 1.18 & 0.23 \\
\hline & Number of floodgates & -0.25 & -0.66 to 0.16 & 0.22 \\
\hline & Watershed area $\left(\mathrm{km}^{2}\right)$ & 0.00 & -0.03 to 0.03 & 0.11 \\
\hline
\end{tabular}

This table includes the model-averaging output for four response variables (Bray-Curtis community dissimilarities, and log response ratios of native fish richness, non-native fish richness, and sculpin abundance) and their associated candidate model sets. Within each analysis, the table lists parameter estimates, $95 \%$ confidence intervals, weights, and the number of models with that parameter. Italicized rows indicate parameters where the $95 \%$ confidence interval did not include zero

for an effect of gate type on floodgate opening times (Table 1). The lack of a substantial effect runs counter to the prevailing body of research (Giannico and Souder 2005; Thomson 2005)

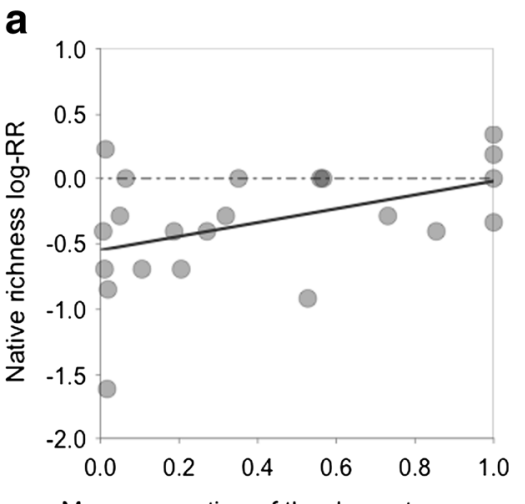

Fig. 6 Relationships between fish richness (log response ratios) for a native and $\mathbf{b}$ non-native richness versus floodgate operations. When the $\log$ response ratio is 0 , there is no difference in richness above and below floodgates. Negative values of the log response ratio correspond with reduced native species richness upstream of the floodgates relative to that found downstream. For example, a $\log \mathrm{RR}$ of -0.5 means there and our result is likely driven by low sample sizes for some of the different gate types. Specifically, there were few manual $(n=2)$ and top-mounted gates $(n=3)$, compared to side-

b

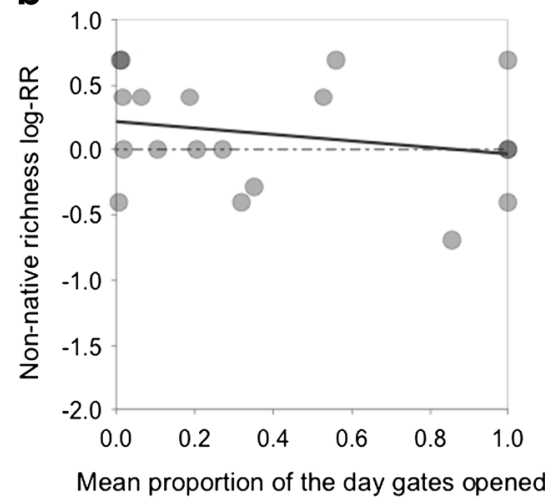

would be $39 \%$ fewer unique taxa above the floodgates. Positive values indicate higher richness upstream of the floodgates than downstream. The linear relationships presented here represent the single-variable linear model comparing a native richness and $\mathbf{b}$ non-native richness log response ratios with floodgate operations and are meant for visualization purposes 
Table 3 Summary of AICc model averaging output for linear models comparing upstream and downstream dissolved oxygen concentrations with floodgate operation data and site-level characteristics

\begin{tabular}{|c|c|c|c|c|}
\hline & Parameter & $\begin{array}{l}\text { Parameter } \\
\text { estimate }\end{array}$ & $\begin{array}{l}95 \% \text { Confidence } \\
\text { interval }\end{array}$ & $\begin{array}{l}\text { Parameter } \\
\text { weight }\end{array}$ \\
\hline \multirow[t]{6}{*}{ Upstream dissolved oxygen } & Intercept & 3.89 & 0.52 to 7.26 & $N A$ \\
\hline & Mean proportion open & 5.89 & 2.03 to 9.75 & 0.93 \\
\hline & Distance upriver $(\mathrm{km})$ & -0.04 & -0.09 to 0.01 & 0.40 \\
\hline & Watershed area $\left(\mathrm{km}^{2}\right)$ & 0.03 & -0.04 to 0.11 & 0.11 \\
\hline & $\%$ Watershed with developed land use & -2.28 & -8.83 to 4.26 & 0.10 \\
\hline & Number of floodgates & -0.11 & -1.3 to 1.08 & 0.09 \\
\hline \multirow[t]{6}{*}{ Downstream dissolved oxygen } & Intercept & 7.59 & 4.32 to 10.86 & $N A$ \\
\hline & Number of floodgates & -0.65 & -1.43 to 0.14 & 0.42 \\
\hline & Mean proportion open & 2.42 & -1.05 to 5.89 & 0.33 \\
\hline & Watershed area $\left(\mathrm{km}^{2}\right)$ & 0.02 & -0.05 to 0.09 & 0.17 \\
\hline & Distance upriver $(\mathrm{km})$ & 0.00 & -0.05 to 0.05 & 0.15 \\
\hline & $\%$ Watershed with developed land use & -0.53 & -6.56 to 5.50 & 0.14 \\
\hline
\end{tabular}

For each parameter, the table lists estimates, $95 \%$ confidence intervals, weights, and the number of models with that parameter. Italicized rows indicate parameters where the $95 \%$ confidence interval did not include zero

mounted gates $(n=13)$ in this study. Pumps represent another design feature that could affect floodgate operations; however, the presence of pumps did not appear to relate to floodgate openings. Pumps are installed at floodgates to move water out of tributaries when the gates are closed for extended periods of time, such as during the freshet, but depending on the settings of the pumps, they can reduce floodgate openings throughout the year by reducing the head differential across the floodgates (Thomson 2005). Pumps were present at a majority of the sites

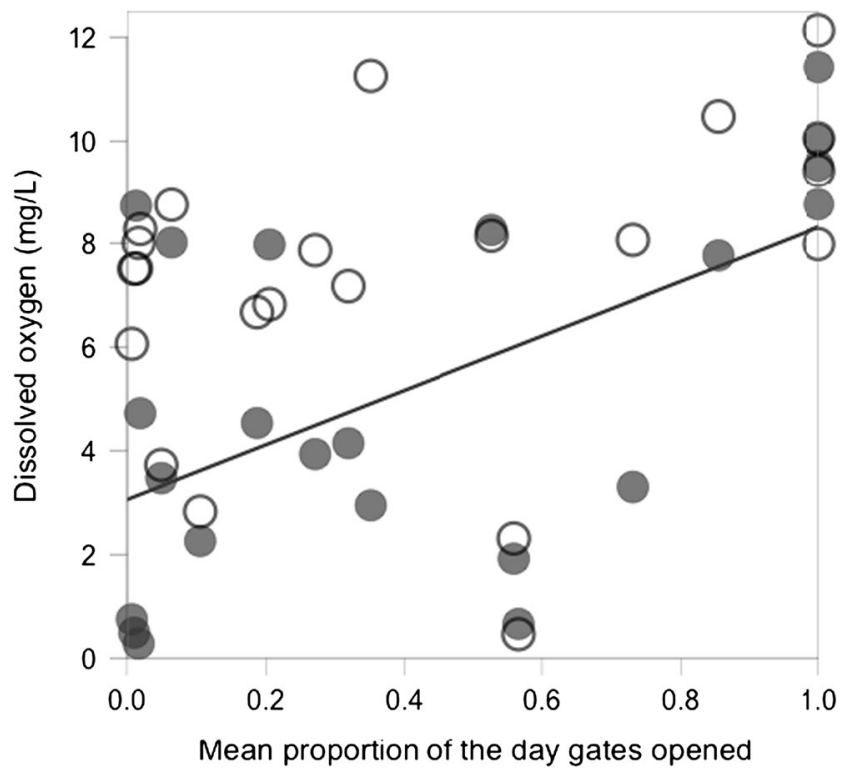

Fig. 7 Dissolved oxygen concentrations (mg/L) measured upstream (filled symbols) and downstream (open) of the floodgates plotted against the mean proportion of the day floodgates opened. The plotted line is based on a single linear model comparing upstream dissolved oxygen concentration with floodgate operations and is meant for visualization purposes in this study $(n=13)$ and varied in their size, number, and "fish-friendliness." There could be variation in the settings of pumps that could allow floodgates to open more frequently, such that looking at "pumps" or "no pumps" as a categorical variable may be too coarse a scale to make generalizations about what they mean for gate openings. Additionally, pumps tend to occur at sites with larger, more developed watersheds (Fig. 4). Even within types of floodgates, there were vast differences in the amount and timing of floodgate opening.

\section{Fish Communities}

This study shows that the level of impact on fish in tidal creeks can vary with floodgate operations. Where floodgates rarely opened, native richness was on average 32\% lower upstream of the floodgates compared to downstream. This corresponds to an average difference of one fewer native species above closed floodgates. Where tributaries did not have floodgates, however, there were no differences in native richness between upstream and downstream sections, as predicted. In addition, fish communities above and below floodgates were most dissimilar where floodgates rarely opened, but were more similar at sites that opened for longer periods of time or that did not have floodgates. Specifically, on average, fish communities were $23 \%$ more similar in fully connected sites than where they were separated by closed floodgates. Floodgates have been associated with reduced native fish diversity in tidal creeks in the Lower Fraser (Scott et al. 2016), and around the world (Pollard and Hannan 1994; Halls et al. 1998; Kroon and Ansell 2006). Furthermore, several studies have demonstrated that fish communities in gated creeks differ from those in unrestricted creeks (Kroon and Ansell 2006; 
Scott et al. 2016). Others have discussed mitigating these impacts through structural and operational changes, such as opening floodgates for longer periods of time (Pollard and Hannan 1994; Franklin and Hodges 2015). For example, Boys et al. (2012) found that structurally modifying floodgates or intermittently opening them led to improved fish passage and shifted fish communities back towards reference communities in Australian tidal creeks. Our body of work builds on these important case studies to quantify the relationship between floodgate openness and their environmental impacts. While outright removal of many floodgates may not be a valid option due to flood risk, our data provides strong evidence that opening floodgates more often would reduce disruptions to tidal creek fish communities.

Individual fish taxa and subgroups appeared to differ in their sensitivity to floodgate operations. For example, three-spined sticklebacks (Gasterosteus aculeatus) and juvenile cyprinids, the two most commonly captured taxa in this study, did not show any differences in numbers in relation to floodgate operations. Three-spined sticklebacks are often abundant in tidal creeks in the Pacific Northwest, including those with tide gates (Tonnes 2006; Greene et al. 2012; Scott et al. 2016). In contrast, prickly sculpins were more abundant on average in creeks where floodgates opened more often or where there were no floodgates. Where floodgates never or rarely opened, however, the upstream sculpin abundance was on average one quarter of that found below the floodgates. Additionally, we observed sculpins upstream of floodgates at only four sites, though we observed them downstream of floodgates at ten sites (Online Resource 3). Sculpins may be particularly vulnerable to altered connectivity in river systems (Favaro and Moore 2015) and prickly sculpin abundances have previously been found to be lower in gated creeks than in non-gated creeks (Scott et al. 2016). Non-native fishes, such as pumpkinseed sunfish and largemouth bass, did not appear to be sensitive to differences in floodgate operations, although previous studies have found that non-native species tend to be more abundant in areas upstream of floodgates than in creeks without floodgates (Franklin and Hodges 2015; Scott et al. 2016). Due to the timing of sampling, our study did not fully assess the impacts of floodgate operations on juvenile salmon. Although tidal creeks and wetlands can be key rearing habitats for juvenile coho and Chinook salmon in the spring and early summer, most individuals are unlikely to remain in these habitats by late summer (Levy and Northcote 1982; Craig et al. 2014; Scott et al. 2016). Our fish sampling regime was focused on the late summer and thus provided a snapshot of impacts for this season when hypoxic conditions occur near floodgates (Gordon et al. 2015; Scott et al. 2016). Our sampling occurred after the widespread spring/early summer use of tidal channels by migrating juvenile salmon; additional sampling early in the season could have captured effects of floodgate operations on juvenile salmon within these fish communities. Previous research in a subset of this study's sites found that creeks with floodgates had
2.5 times fewer salmon than sites without floodgates (Scott et al. 2016). Given that the impacts of floodgates to fish communities will be expressed across the annual cycle of fish migration and dispersal (Scott et al. 2016), our results should be considered conservative. Given that floodgates can impact juvenile salmonids in these systems (Greene et al. 2012; Scott et al. 2016), future studies could demonstrate stronger relationships between fish communities and floodgate operations with additional sampling in the spring and early summer. More broadly, future studies could directly investigate how floodgate operations and designs impact passage of juvenile salmonids and other individual fish taxa across the seasonal patterns of their life cycles.

\section{Water Quality and Floodgate Engineering}

Floodgate operations were associated with dissolved oxygen concentrations upstream of floodgates, but not downstream (Fig. 7, Table 3). As previously recorded in this region (Gordon et al. 2015), we observed lower dissolved oxygen concentrations above floodgates than in reaches below the floodgates (Fig. 7). We build on this result by showing a link between floodgate openness and the severity of the upstream hypoxia (Table 3). This correlation was evident whether we used all floodgate operations data (Table 3) or only observations from July and August (Online Resource 5). These data indicate that increases in water exchange from changes to floodgate operations could result in water quality improvements (Raposa and Roman 2003). For example, increasing opening times could relieve hypoxic conditions found above floodgates by restoring variable flows and tidal flushing to tributaries (Franklin and Hodges 2015). Additionally, hypoxic conditions above floodgates tend to be most pronounced in the late summer (Scott et al. 2016), so the impact of floodgate operations on water quality may vary seasonally. Future work could measure dissolved oxygen concentrations throughout the year to better understand how floodgate openings affect water quality on smaller time scales, and to determine if there are times of year that floodgate operations could be more effectively modified to improve water quality.

While our analyses focused on the amount of time that floodgates opened, there are other aspects of floodgate engineering that may influence their environmental impacts. The conditions at individual floodgates can restrict fish passage opportunities to a subset of the time gates remain open (Bass 2010). Fully open floodgates may still share many characteristics of culverts that represent partial barriers to fish passage, such as the potential to produce high water velocities or to become inaccessible to fish if installation heights do not match water levels (Haro et al. 2004; Bass 2010). For example, culverts and floodgates might become "perched" at low tide if the gates are installed higher than low tide depth, thereby preventing fish from traveling upstream through an open gate (Bass 2010). Conversely, if floodgates are installed too low, floodgates may remain underwater for long periods of time and therefore be prevented from opening 
(Giannico and Souder 2005). Furthermore, the angle of floodgate opening could limit the size of fish that can pass through an open floodgate (Bass 2010; Greene et al. 2012). In addition, we note that our study did not examine whether floodgates that opened more maintained a similar level of flood protection. Such details could aid in crafting floodgate designs that would explicitly evaluate the potential trade-offs between fish passage and flood protection.

\section{Conclusions and Implications}

Our study had two key findings. First, we discovered substantial variation in the amount of time floodgates open at sites across the region - with many floodgates opening rarely while others opened more often - as well as seasonal variation in floodgate operations. Second, this variation in floodgate operation was linked to water quality and native fish communities. In coastal deltas around the world, managers are faced with aging flood control infrastructure, environmental protection, and projected sea-level rise. In response to these challenges, managers are starting to plan for infrastructure upgrades and policy changes. For example, a Lower Mainland Flood Management Strategy is in development for the Lower Fraser River region to coordinate flood mitigation efforts (Fraser Basin Council 2014). This regional flood strategy will identify areas of improvement in flood management policy and infrastructure for public safety and climate change adaptation. Given that there are more than two million people in this region, flood protection is an obvious priority for this planning process. Yet, tidal creeks in this region represent important habitats for numerous fish species, including commercially important species such as salmon, which are negatively impacted by flood protection structures (Scott et al. 2016). There is an opportunity to use data such as those presented here to inform floodgate operations to improve water quality and connectivity for fish while still protecting developed areas from flooding.

Acknowledgements We are grateful to Mike Bradford and two anonymous reviewers for their valuable feedback on drafts of this manuscript. Many thanks also go to field assistants Ellika Crichton and Daniel Tan and many volunteers who helped in the field.

Funding Information This project received funding from Simon Fraser University, the Liber Ero Foundation, and the Natural Science and Engineering Council of Canada.

Compliance with Ethical Standards Sampling was approved by the University Animal Care Committee at Simon Fraser University (protocol number 1158B-11) and by scientific collection permits from Fisheries and Oceans Canada and the Ministry of Forests, Lands, and Natural Resource Operations.

Open Access This article is distributed under the terms of the Creative Commons Attribution 4.0 International License (http:// creativecommons.org/licenses/by/4.0/), which permits unrestricted use, distribution, and reproduction in any medium, provided you give appropriate credit to the original author(s) and the source, provide a link to the Creative Commons license, and indicate if changes were made.

\section{References}

Bartoń, Kamil. 2015. MuMIn: Multi-Model Inference. R package version 1.15.1. http://cran.r-project.org/package=MuMIn. Accessed 7 April 2016.

Bass, A. L. 2010. Juvenile coho salmon movement and migration through tide gates. (Master's Thesis) Retrieved from Oregon State University Library, Corvallis, OR. https://ir.library.oregonstate.edu/xmlui/ bitstream/handle/1957/17428/BassArthurL2010.pdf?sequence $=1$. Accessed 7 April 2016.

Bates, D., M. Maechler, B. Bolker, S. Walker, R.H.B. Christensen, H. Singmann, B. Dai, and G. Grothendieck. 2015. Package 'Ime4'. R package version 1.1-9. http://cran.r-project.org/package=lme4. Accessed 7 April 2016.

BC MFLNRO (Ministry of Forests, Lands, and Natural Resource Operations). 2011. Lower Mainland Dike \& Emergency Maps. http://www.env.gov.bc.ca/wsd/public_safety/flood/fhm-2012/maps. html. Accessed 7 April 2014.

Beck, M.W., K.L. Heck Jr., K.W. Able, D.L. Childers, D.B. Eggleston, B.M. Gillanders, B.S. Halpern, C.G. Hays, K. Hoshino, T.J. Minello, R.J. Orth, P.F. Sheridan, and M.P. Weinstein. 2001. The identification, conservation, and management of estuarine and marine nurseries for fish and invertebrates. Bioscience 51 (8): 633-641.

Birtwell, I.K., C.D. Levings, J.S. Macdonald, and I.H. Rogers. 1988. A review of fish habitat issues in the Fraser River system. Canadian Water Resources Association Journal 6: 76-88.

Bornhold, B. D. 2008. Projected Sea Level Changes for British Columbia in the 21 st Century, 1-12. British Columbia Ministry of Environment. Library and Archives Canada. http://www2.gov.bc. $\mathrm{ca} /$ assets/gov/environment/climate-change/policy-legislation-andresponses/adaptation/sea-level-rise/sea-level-changes-08.pdf. Accessed 7 April 2016.

Boys, C.A., F.J. Kroon, T.M. Glasby, and K. Wilkinson. 2012. Improved fish and crustacean passage in tidal creeks following floodgate remediation. Journal of Applied Ecology 49: 223-233.

Burnham, K.P., and D.R. Anderson. 2002. Model selection and multimodel inference: a practical information-theoretic approach. 2nd ed. New York: Springer-Verlag.

Charland, J. 1998. Tide gate modifications for fish passage and water quality enhancement, 1-15. Garibaldi: Tillamook Bay National Estuary Project.

Craig, B.E., C.A. Simenstad, and D.L. Bottom. 2014. Rearing in natural and recovering tidal wetlands enhances growth and life-history diversity of Columbia estuary tributary coho salmon Oncorhynchus kisutch population. Journal of Fish Biology 85: 31-51.

DFO (Fisheries and Oceans Canada). 1999. Lower Fraser Valley Streams Strategic Review. Fisheries and Oceans Canada. http:// www.dfo-mpo.gc.ca/Library/240006.pdf. Accessed 7 April 2016.

Doehring, K., R.G. Young, J. Hay, and A.J. Quarterman. 2011. Suitability of dual-frequency identification sonar (DIDSON) to monitor juvenile fish movement at floodgates. New Zealand Journal of Marine and Freshwater Research 45: 413-422.

ESRI. 2014. ArcGIS desktop: release 10.2. [software]. Redlands: Environmental Systems Research Institute.

Favaro, C., and J.W. Moore. 2015. Fish assemblages and barriers in an urban stream network. Freshwater Science 34: 991-1005.

Franklin, P.A., and M. Hodges. 2015. Modified tide gate management for enhancing instream habitat for native fish upstream of the saline limit. Ecological Engineering 81: 233-242. 
Fraser Basin Council. 2010a. Environmental protection in flood hazard management: a guide for practitioners. http://www.fraserbasin.bc. ca/_Library/Water/report flood and environmental protection 2010.pdf. Accessed 7 April 2016.

Fraser Basin Council. 2010b. The Fraser: a Canadian heritage river. The Canadian Heritage Rivers Board. http://www.fraserbasin.bc.ca/ Library/Water/report_chr_fraser_river_2010.pdf. Accessed 7 April 2016.

Fraser Basin Council. 2014. Introducing the lower mainland flood management strategy. http://www.fraserbasin.bc.ca/_Library/Media/ backgrounder_lmfls.pdf. Accessed 24 April 2016.

Giannico, G. R., and J. A. Souder. 2004. The effects of tide gates on estuarine habitats and migratory fish. Oregon Sea Grant. http:// www.oregon.gov/OWEB/MONITOR/docs/mr_effectsoftidegates. pdf. Accessed 7 April 2016.

Giannico, G. A., and J. A. Souder. 2005. Tide gates in the Pacific Northwest: operation, types and environmental effects. Oregon Sea Grant. http://seagrant.oregonstate.edu/sites/seagrant. oregonstate.edu/files/sgpubs/onlinepubs/t05001.pdf. Accessed 7 April 2016.

Google Inc. (2015). Google Earth (Version 7.1.5.1557) [Software] http:// earth.google.ca/. Accessed 10 May 2015.

Gordon, J., M. Arbeider, D. Scott, S.M. Wilson, and J.W. Moore. 2015. When the tides don't turn: floodgates and hypoxic zones in the lower Fraser River, British Columbia, Canada. Estuaries and Coasts 38 (6): 2337-2344.

Greene, C., J. Hall, E. Beamer, R. Henderson, and B. Brown. 2012. Biological and physical effects of "fish-friendly" tide gates. http:// skagitcoop.org/wp-content/uploads/EB2673_Greene-et-al_2012. pdf. Accessed 7 April 2016.

Halls, A.S., D.D. Hoggarth, and K. Debnath. 1998. Impact of flood control schemes on river fish migrations and species assemblages in Bangladesh. Journal of Fish Biology 53: 358-380.

Hammer, O., .AT Harper, and P.D. Ryan. 2012. DPAST: paleontological statistics software package for education and data analysis. (Version 2.17). Natural History Museum, University of Oslo. http://folk.uio. no/ohammer/past/index_old.html/. Accessed 1 February 2016.

Haro, A., T. Castro-Santos, J. Noreika, and M. Odeh. 2004. Swimming performance of upstream migrant fishes in openchannel flow: a new approach to predicting passage through velocity barriers. Canadian Journal of Fisheries and Aquatic Sciences 61: 1590-1601.

Hastie, T.J., and D. Pregibon. 1992. Generalized linear models. In Statistical models in S, ed. J.M. Chambers and T.J. Hastie. Pacific Grove: Wadsworth \& Brooks/Cole.

Hedges, L.V., J. Gurevitch, and P.S. Curtis. 1999. The meta-analysis of response ratios in experimental ecology. Ecology 80 (4): 1150-1156.

Kroon, F.J., and D.H. Ansell. 2006. A comparison of species assemblages between drainage systems with and without floodgates: implications for coastal floodplain management. Canadian Journal of Fisheries and Aquatic Sciences 63: 2400-2417.

Legendre, P., and L.F.J. Legendre. 2012. Numerical ecology. Third ed. Oxford: Elsevier.

Levings, C.D., D.E. Boyle, and T.R. Whitehouse. 1995. Distribution and feeding of juvenile Pacific salmon in freshwater tidal creeks of the lower Fraser River, British Columbia. Fisheries Management and Ecology 2: 299-308.

Levy, D.A., and T.G. Northcote. 1982. Juvenile salmon residency in a marsh area of the Fraser River estuary. Canadian Journal of Fisheries and Aquatic Sciences 39: 270-276.
LGL Limited, Musqueam Indian Band, Mountain Station Consultants Inc, Kerr Wood Leidal Associated Limited. 2009. Prioritization of and rehabilitation considerations for fish migration impediments in the Lower Fraser River. Vancouver, BC: Fraser Salmon and Watersheds Program. https://www.psf.ca/sites/default/files/Final Impediment_Report.pdf. Accessed 7 April 2016.

Lotze, H.K., H.S. Lenihan, B.J. Bourque, R.H. Bradbury, R.G. Cooke, M.C. Kay, S.M. Kidwell, M.X. Kirby, C.H. Peterson, and J.B.C. Jackson. 2006. Depletion, degradation, and recovery potential of estuaries and coastal seas. Science 312: 1806-1809.

Mazerolle, M.J. 2015. AICcmodavg: Model selection and multimodel inference based on (Q)AIC(c). R package version 2.0-3. http:// CRAN.R-project.org/package=AICcmodavg. Accessed 7 April 2016

Oksanen, J., F.G. Blanchet, R. Kindt, P. Legendre, P.R. Minchin, R.B. O'Hara, G.L. Simpson, P.Solymos, M.H.H. Stevens, and H. Wagner. 2015. vegan: Community Ecology Package. R package version 2.3-0. http://cran.r-project.org/package=vegan. Accessed 7 April 2016.

Pollard, D.A., and J.C. Hannan. 1994. The ecological effects of structural flood mitigation works on fish habitats and fish communities in the lower Clarence River system of south-eastern Australia. Estuaries 17: 427-461

Portnoy, J.W. 1991. Summer oxygen depletion in a diked New England estuary. Estuaries 14: 122-129.

Portnoy, J.W., and J.R. Allen. 2006. Effects of tidal restrictions and potential benefits of tidal restoration on fecal coliform and shellfishwater quality. Journal of Shellfish Research 25: 609-617.

R Development Core Team. 2015. R: a language and environment for statistical computing (version 3.1.2). Vienna: R Foundation for Statistical Computing.

Raposa, K.B., and C.T. Roman. 2003. Using gradients in tidal restriction to evaluate nekton community responses to salt marsh restoration. Estuaries 26: 98-105.

Ritter, A.F., K. Wasson, S.I. Lonhart, R.K. Preisler, A. Woolfolk, K.A. Griffith, S. Connors, and K.W. Heiman. 2008. Ecological signatures of anthropogenically altered tidal exchange in estuarine ecosystems. Estuaries and Coasts 31: 554-571.

Schielzeth, H. 2010. Simple means to improve the interpretability of regression coefficients. Methods in Ecology and Evolution 1: 103-113.

Scott, D.C., M. Arbeider, J. Gordon, and J.W. Moore. 2016. Flood mitigation structures transform tidal creeks from nurseries for native fishes to non-native hotspots. Canadian Journal of Fisheries and Aquatic Sciences. https://doi.org/10.1139/cjfas-2015-0311.

Thomson, A. 1999. Study of flood proofing barriers in lower mainland fish bearing streams. Fisheries and Oceans Canada.

Thomson, A. R. 2005. Flood box management in southwestern British Columbia. BC Ministry of Water, Land and Air Protection.

Tockner, K., and J.A. Stanford. 2002. Riverine flood plains: present state and future trends. Environmental Conservation 29: 308-330.

Tonnes, D.M. 2006. Fish use and water quality in select channels regulated by tide gates within the Snohomish River Estuary. Technical Assessment, National Marine Fisheries Service.

Viola, D.V., E.A. Mordecai, and A.G. Jaramillo. 2010. Competition-defense tradeoffs and the maintenance of plant diversity. Proceedings of the National Academy of Sciences 107 (40): 17217-17222.

Wright, G.V., R.M. Wright, and P.S. Kemp. 2014. Impact of tide gates on the migration of juvenile sea trout, Salmo trutta. Ecological Engineering 71: 615-622. 